\title{
Propofol to Increase Colorectal Cancer Screening in Portugal
}

\author{
Propofol como Forma de Aumentar o Rastreio Endoscópico do Cancro do \\ Cólon e Reto em Portugal
}

\author{
Alexandre Oliveira FERREIRA ${ }^{1}$, Andrea RIPHAUS ${ }^{2}$ \\ Acta Med Port 2014 Sep-Oct;27(5):541-542 \\ Keywords: Colorectal Neoplasms; Hypnotics and Sedatives; Propofol; Endoscopy, Gastrointestinal; Colonoscopy. \\ Palavras-chave: Neoplasia Colo-Rectal; Hipnóticos e Sedativos; Propofol; Endoscopia Gastrointestinal; Colonoscopia.
}

Gastrointestinal (GI) endoscopy is an invasive procedure and it has been so since the introduction of the flexible fiberscope in the 1950's. An esophagogastroduodenoscopy (EGD) is an unpleasant experience and so is colonoscopy, which is also considerably painful. Endoscopic retrograde cholangiopancreatography (ERCP) and endoscopic ultrasound can be even worse from the patient viewpoint, being inadvisable to perform it without adequate sedation.

To overcome such unpleasantness, endoscopists have been searching for ways to minimize it since the late 50's. Attempts have been made throughout the history of $\mathrm{GI}$ endoscopy, from the development of transnasal endoscopes, the utilization of $\mathrm{CO} 2$ insufflation and water immersion techniques for colonoscopy. However, the most significant advances achieved have been on the sedation aspect of the procedures. From meperidine alone or a cumbersome premedication with pentobarbital and meperidine followed by a topical laryngeal lignocaine spray with a transtracheal or translaryngeal injection of xylocaine reported in 1960 for EGD, to the evaluation of diazepam in 1965, when it was shown to improve the rate of satisfactory examinations by $20 \%$ comparing to meperidine alone. This was the 'kick starter' for the beginning of the so called 'traditional sedation', comprising a combo of a benzodiazepine and an opioid. By that time, the search for the optimal agent was far from the end and diazepam was nowhere near the optimum agent as defined by Berry LH: it should "produce optimal relaxation, have a rapid onset of action, last for an optimum period of time, and rapidly dissipate thereafter. In addition it should be devoid of systemic and local toxicity".

In the 80's a 'new kid on the block' arrived, the name was midazolam. It had a better pharmacokinetic and pharmacodynamic profile comparing to diazepam. Hence, it was considered a major improvement in the endoscopy suite. It reduced both induction and recovery times and increased patients' amnesia rate; however it was not devoid of systemic toxicity. Soon after its introduction there were reports to the FDA of severe adverse events including 131 serious cardiorespiratory complications and 71 deaths. Apart from these reports, the supposed increased relative risk was never demonstrated. Since the 80's, midazolam has gained worldwide acceptance and it's probably the most often used agent. However, propofol, an ultra-short acting hypnotic agent, is even better than midazolam ${ }^{1,2}$ as it is very close to the optimal sedative agent definition. Propofol has been shown to increase patient and endoscopist satisfaction, to decrease induction, wake up and psychomotor recovery times. A faster recovery has impact in patient comfort and in endoscopy unit productivity.

Propofol has an excellent track record in low risk patients (better than traditional sedation) also when performed by endoscopists or trained nursing staff, ${ }^{1,3}$ in what is known as non-anesthesiologist administration of propofol (NAAP). This modality is currently endorsed by several societal guidelines, including the four major American societies (AGA, ACG, ASGE and AASLD), the European Society of Gastrointestinal Endoscopy (ESGE) and, however briefly, the European Society of Anaesthesiolgy. ${ }^{4}$ In fact, for the sedation of low risk patients, the cost-effectiveness of having an anesthetist is not satisfactory, being calculated by Rex et al. to be in the range of $\$ 5.3$ million/life year in a study with a mortality rate of $1: 161515$ cases $^{3}$ which does not exceed published mortality rates for general anesthesia which is 1:13322 (overall) and 1:200200 in ASA I-II. ${ }^{5}$

Propofol sedation has been gaining momentum in the last decade in several European countries (Germany, Switzerland, Austria, Denmark) but despite the existing evidence and the endorsement by scientific societies, propofol is still underused in most countries. ${ }^{6}$ There are several reasons behind this phenomenon. One is the theoretical possibility of clinically significant side effects that include respiratory and circulatory depression, despite the evidence gathered so far, that understates that nonanesthesiologist administration of propofol is as safe as endoscopist directed 'traditional sedation', as shown in several meta-analysis., ${ }^{1,2}$ Another reason is the position of some anesthesiology societies, motivated by financial aspects protecting a multi-million business with arguments almost entirely devoid of any evidence base. ${ }^{7}$

Sedation for colonoscopy might be the most crucial

1. Serviço de Gastrenterologia. Centro Hospitalar do Algarve. Portimão. Portugal.

2. Department of Medicine and Gastroenterology. KRH Klinikum Agnes Karll Laatzen. Hannover-Laatzen. Germany.

Recebido: 24 de Abril de 2014 - Aceite: 04 de Agosto de 2014 | Copyright @ Ordem dos Médicos 2014 
aspect in this setting, as screening colonoscopy is the number one endoscopic procedure and it has been shown to be effective in reducing both incidence and mortality of colorectal cancer (CCR). ${ }^{8}$ CCR is the $3^{\text {rd }}$ most common cancer in the world and in Portugal. It is accountable for over 600000 deaths worldwide and 3800 - in Portugal alone, representing over 12000 lost life years, which is higher than breast cancer.

In Portugal, like in most European countries, the CCR incidence is steadily increasing. This can be attributed to several factors, with aging probably being the number one contributor. However, some western countries like the USA, and more recently Germany, have been able to start decreasing CCR incidence, which has been attributed primarily to the implementation of an effective colonoscopy CCR screening program. ${ }^{9}$ It has been estimated that for each $1 \%$ increase in total colonoscopy rate there is a $3 \%$ reduction in CCR related death hazard. ${ }^{10}$ Some may argue the lack of randomized clinical trials to support colonoscopy instead of sigmoidoscopy but the indirect evidence is quite significant and the strength of the evidence is increasing..$^{8-10}$ These studies support the guidelines that consider colonoscopy as the preferred method.

Colonoscopy is not a well-loved procedure and most people would pass on it if there was a reasonable option. Our goal as healthcare professionals is to improve the value for patients. Colonoscopy offers the best value for CCR screening. It has been shown that patients prefer sedated colonoscopy and that adequate sedation improves procedural quality indicators without clinically significant adverse events. Therefore it is not ethical to offer colonoscopy without sedation in the $21^{\text {st }}$ century (unless specifically asked for by the patient). Propofol sedation is the best option for colonoscopy. NAAP sedation offers the best value for low risk (ASA I-II) patients. NAAP may have the

\section{REFERENCES}

1. Singh H, Poluha W, Cheung M, Choptain N, Baron KI, Taback SP. Propofol for sedation during colonoscopy. Cochrane Database Syst Rev. 2008:CD006268.

2. Wang D, Chen C, Chen J, Xu Y, Wang L, Zhu Z, et al. The use of propofol as a sedative agent in gastrointestinal endoscopy: a metaanalysis. PloS one. 2013;8:e53311.

3. Rex DK, Deenadayalu VP, Eid E, Imperiale TF, Walker JA, Sandhu K, et al. Endoscopist-directed administration of propofol: a worldwide safety experience. Gastroenterology. 2009;137:1229-37.

4. Dumonceau JM, Riphaus A, Aparicio JR, Beilenhoff U, Knape JT, Ortmann M, et al. European Society of Gastrointestinal Endoscopy, European Society of Gastroenterology and Endoscopy Nurses and Associates, and the European Society of Anaesthesiology Guideline: Non-anesthesiologist administration of propofol for $\mathrm{Gl}$ endoscopy. Endoscopy. 2010;42:960-74.

5. Lagasse RS. Anesthesia safety: model or myth? A review of the published literature and analysis of current original data. Anesthesiology. potential to increase adherence to screening colonoscopy as it may help improve the population perception of colonoscopy. Even though the impact in patient adherence is not quantified it must be clinically significant (even if it increases colonoscopy rate in just 1\%).

Offering patients a 'painless' colonoscopy with high quality endoscopic 'experience', might be the best option to motivate our patients for screening colonoscopy and ideally stimulate their relatives and friends to undertake CCR screening as well.

It should, therefore, be considered a public health priority to allocate the necessary resources in order to make CCR screening a reality and as effective as possible. A high standard regarding the quality for sedation is an essential aspect of colonoscopy, more so when we are submitting conscious healthy individuals to an invasive and painful examination. Setting the standards for sedation in endoscopy was already a main focus addressed by many Gastrointestinal Societies, which led to the development of the current international guidelines.

The creation of a national curriculum for sedation is desirable. This could include professional courses for residents and nurses and accredited formation units, with support from the local anesthesiology professionals. This format might be easily adopted from the already existing German and European specifications and seem to be the logical step to improve patients safety in gastrointestinal endoscopy in every country.

\section{CONFLICTS OF INTEREST}

The authors declared no conflicts of interest.

\section{FUNDING SOURCES}

No subsidies or grants contributed to this work.

2002;97:1609-17.

6. Riphaus A, Macias-Gomez C, Devière J, Dumonceau JM. Propofol, the preferred sedation for screening colonoscopy, is underused. Results of an international survey. Dig Liver Dis. 2012;44:389-92.

7. Perel A. Non-anaesthesiologists should not be allowed to administer propofol for procedural sedation: a Consensus Statement of 21 European National Societies of Anaesthesia. Eur J Anaesthesiol. 2011;28:580-4.

8. Nishihara R, Wu K, Lochhead P, Morikawa T, Liao X, Qian ZR, et al. Long-term colorectal-cancer incidence and mortality after lower endoscopy. N Engl J Med. 2013;369:1095-105.

9. Schnoor M, Waldmann A, Eberle A, Holleczek B, Katalinic A. Colorectal cancer incidence in Germany: stage-shift 6 years after implementation of a colonoscopy screening program. Cancer Epidemiol. 2012;36:41720.

10. Rabeneck L, Paszat LF, Saskin R, Stukel TA. Association between colonoscopy rates and colorectal cancer mortality. Am J Gastroenterology. 2010;105:1627-32. 


\section{Propofol to Increase Colorectal Cancer Screening in Portugal}

Acta Med Port 2014:27:541-542

Publicado pela Acta Médica Portuguesa, a Revista Científica da Ordem dos Médicos

Av. Almirante Gago Coutinho, 151

1749-084 Lisboa, Portugal.

Tel: +351218428215

E-mail: submissao@actamedicaportuguesa.com

www.actamedicaportuguesa.com

ISSN:0870-399X | e-ISSN: 1646-0758

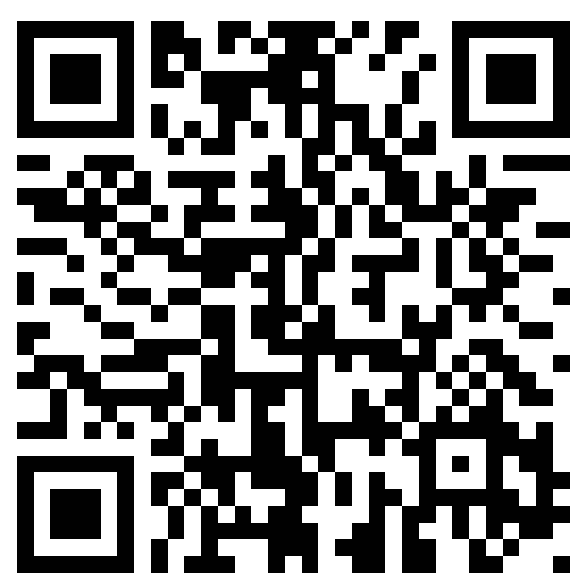

